Televisión y participación política transnacional. Las audiencias de televisión italiana en Buenos Aires

María Soledad Balsas

Ciudad Autónoma de Buenos

Aires: Prometeo Libros, 2018.

\section{Desde los ojos de las audiencias: la televisión italiana y la política transnacional}

\author{
Mariana Patricia Busso
}

Universidad Nacional de Rosario - CONICET

Desde un a priori no exento de prejuicios, podría pensarse que un libro que aborde los vínculos entre participación política, migraciones y televisión no tendría nada demasiado nuevo para agregar al tema. Sin embargo, Televisión y participación politica transnacional. Las audiencias de televisión italiana en Buenos Aires, de María Soledad Balsas (Buenos Aires: Prometeo Libros, 2018, 259 páginas) representa una contundente desmentida y, a la vez, una interesante puesta en discusión de muchos aspectos irresueltos de esos debates.

Producto de una investigación financiada por CONICET (Consejo Nacional de Investigaciones Científicas y Técnicas, Argentina), institución en la que la autora se desempeña en calidad de Investigadora Adjunta, este libro se ubica en el cruce entre los estudios sobre medios y, en particular, los estudios sobre audiencias; las investigaciones sobre participación política y aquellas sobre migración y diáspora. Intersecciones no siempre cómodas, y que demandan la articulación de abordajes teóricos y metodológicos provenientes de distintas tradiciones, que la autora logra acabadamente.

Movida por el objetivo de analizar cómo la televisión italiana (RAI) destinada a las y los italianos en el exterior —en particular, a ciudadanas y ciudadanos italianos residentes en Buenos Aires, Argentina - incide en la participación política de estos (fundamentalmente, en los procesos de votación), Balsas realiza una compleja construcción de su objeto de estudio, mostrando la necesidad de hacer intervenir saberes provenientes de distintos ámbitos (las ciencias de la comunicación, la sociología, la teoría política...), y dando cuenta también de las perplejidades y las dificultades propias del proceso de investigación. El resultado supone no solo dilucidaciones en relación al interrogante que guía la organización del libro, sino que también plantea preguntas - y propone respuestas - en relación a los procesos políticos que involucran a comunidades transnacionales en relación con el ecosistema mediático, y a la conformación misma de este último, problematizando puntualmente el rol de la «vieja» televisión.

La aparición en primer plano de la televisión (entendida aquí tanto como medio $\mathrm{y}$ artefacto que forma parte de la vida cotidiana), para el caso, es una de las apuestas incómodas que realiza el libro. Pero no para certificar su carácter obsoleto - como mucho se ha dicho y escrito en los últimos tiempos, signados por el auge de las pla-

- Doctora en Comunicación Social (UNR - Argentina). Es Investigadora Asistente en CONICET y docente JTP en la cátedra Lenguajes I de la Licenciatura en Comunicación Social (Facultad de Ciencia Política y RR.II. - UNR). Es miembro del Comité Académico del CIM - Centro de Investigaciones en Mediatizaciones y del Grupo de Estudios sobre Migraciones (Facultad de Ciencia Política y RR.II. - UNR). 
taformas online-, sino todo lo contrario. Como muestra Balsas, para el particular colectivo estudiado en Televisión y participación política transnacional la existencia del canal internacional de la RAI no es un asunto sin importancia, como tampoco lo son los contenidos de su grilla o la imagen de las audiencias que propone.

Así, el acto mismo de mirar televisión vuelve a adquirir en el libro de Balsas un lugar de privilegio: sin contar con transmisión libre vía Internet de los contenidos de la televisión italiana, su canal televisivo público destinado a los italianos en el exterior parece erigirse en una de las pocas vías de contacto oficiales con esa Italia que, para algunos, es incluso el país de nacimiento. Como resulta de la investigación de la autora, se dirimen allí cuestiones identitarias ligadas a las nociones de origen y de colectividad, por ejemplo, en una nueva demostración de la relevancia del tema en el marco de los estudios sobre migraciones. Asimismo, encontramos que la recepción de la RAI por parte de sus audiencias en Buenos Aires pone también en juego mecanismos ligados a la heterorrepresentación que de esos ciudadanos en el exterior se realiza desde Italia, en lo que pareciera confirmar la importancia de la programación o grilla televisiva (su regularidad diaria y el particular contacto que aquella propone entre el flujo televisivo y los sujetos) a la hora de construir sentidos y de organizar una suerte de presencia - o no- con otros que comparten el visionado (Fechine, 2014) ${ }^{1}$; en este caso, desde el otro lado del océano.

Este último aspecto resulta sumamente relevante, no solo en relación a la contribución que realiza para los estudios sobre el impacto de las tecnologías mediáticas en relación a las migraciones (Oiarzabal y Reips, $2012^{2}$, entre otros), sino porque permite problematizar el rol de medios como la televisión en función de la creación de vínculos transnacionales; en el caso que privilegia Balsas, materializados en el voto de ciudadanos italianos en la Argentina. Es en relación a este interrogante, asimismo, donde aparece otra de las grandes contribuciones del libro, ligadas a la explicitación de su estrategia metodológica.

En efecto, sin esquivar las dificultades halladas ni las posibles objeciones que pudieran levantarse sobre la cuestión, Balsas detalla con minuciosidad y rigor los avatares que signaron la elaboración del andamiaje metodológico empleado en su trabajo, en lo que se trata sin dudas de una acción de destacable rareza en este tipo de estudios. De este modo, la cocina de la investigación que se nos devela permite hacernos conocer el arduo y fatigoso proceso de selección del grupo a estudiar, de su abordaje mediante distintas técnicas como las entrevistas y los focus group, y de los inconvenientes hallados a lo largo de la implementación de estas técnicas. El resultado, a la luz de cuanto expresado en Televisión y politica transnacional, evidencia no solo esos desafíos a los que se enfrentara oportunamente la autora, sino también la posibilidad de resolverlos de modo crítico y sistemático, dando entidad a su complejidad y poniendo en valor las necesarias contribuciones que surgen del estudio realizado.

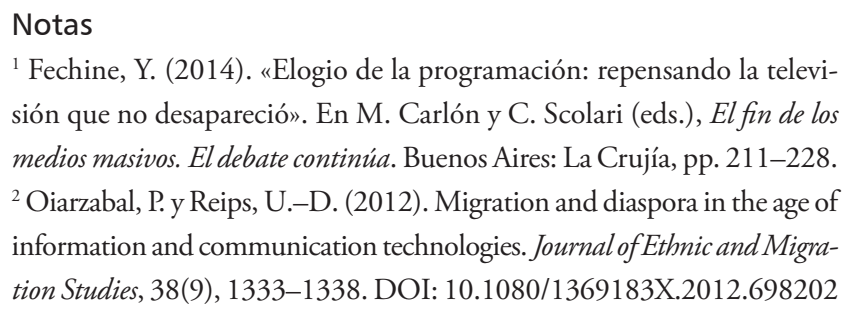

